\title{
It's in the bag: mobile containers in human evolution and child development
}

\author{
Thomas Suddendorf ${ }^{1 \star}$ (D), Kelly Kirkland ${ }^{1}$, Adam Bulley ${ }^{2,3}$, Jonathan Redshaw ${ }^{1}$ \\ and Michelle C. Langley ${ }^{4,5}$

\begin{abstract}
${ }^{1}$ Centre for Psychology and Evolution, School of Psychology, The University of Queensland, St Lucia 4072, Australia,
${ }^{2}$ Department of Psychology, Harvard University, Cambridge, MA 02138, USA, ${ }^{3}$ The University of Sydney, School of Psychology and Brain and Mind Centre, NSW 2050, Australia, ${ }^{4}$ Australian Research Centre for Human Evolution, Environmental Futures Research Institute, Griffith University, Nathan 4111, Australia and ${ }^{5}$ Forensics and Archaeology, School of Environment and Science, Griffith University, Nathan 4111, Australia

*Corresponding author. E-mail: t.suddendorf@psy.uq.edu.au
\end{abstract}

\begin{abstract}
Mobile containers are a keystone human innovation. Ethnographic data indicate that all human groups use containers such as bags, quivers and baskets, ensuring that individuals have important resources at the ready and are prepared for opportunities and threats before they materialize. Although there is speculation surrounding the invention of carrying devices, the current hard archaeological evidence only reaches back some 100,000 years. The dearth of ancient evidence may reflect not only taphonomic processes, but also a lack of attention to these devices. To begin investigating the origins of carrying devices we focus on exploring the basic cognitive processes involved in mobile container use and report an initial study on young children's understanding and deployment of such devices. We gave 3- to 7-year-old children $(N=106)$ the opportunity to spontaneously identify and use a basket to increase their own carrying capacity and thereby obtain more resources in the future. Performance improved linearly with age, as did the likelihood of recognizing that adults use mobile carrying devices to increase carrying capacity. We argue that the evolutionary and developmental origins of mobile containers reflect foundational cognitive processes that enable humans to think about their own limits and compensate for them.
\end{abstract}

Keywords: Foresight; planning; bags; slings; organic material culture; long-distance transport; physical offloading; cognitive development

Media summary: Mobile containers are a key human innovation. Here we examine what is known about their function, evolution, causation and development.

\section{Introduction}

Humans frequently use mobile containers - such as bags, pockets or slings - to carry resources and tools. So ingrained are they to our present lifeways that their importance in human evolution has been somewhat overlooked (Langley \& Suddendorf, 2020). Although there is considerable variation in the materials and techniques employed, as well as in what is commonly carried (see Table 1), a search of the eHRAF World Cultures database found that carrying devices are documented in all hunter-fishergatherer communities and other societies across the globe. Why are mobile containers used universally by humans, and what cognitive processes precipitated their invention?

To lay the foundations, we follow Tinbergen (1963) in examining this phenomenon from the four fundamental biological perspectives he called survival value, evolution, causation and ontogeny. Tinbergen's

(c) The Author(s), 2020 Published by Cambridge University Press on behalf of Evolutionary Human Sciences. This is an Open Access article, distributed under the terms of the Creative Commons Attribution licence (http://creativecommons.org/licenses/by/4.0/), which permits unrestricted re-use, distribution, and reproduction in any medium, provided the original work is properly cited. 
Table 1. Recorded uses of mobile containers in hunter-gatherer ethnographies.

Review of the ethnographic literature describing the lifeways of hunter-gatherer communities in Africa, Australia, Asia and the Americas finds the following specific mentions of mobile container use:

\begin{tabular}{ll}
\hline Bathing & Carrying foodstuffs \\
\hline Carrying equipment (various items) & Carrying infants \\
\hline Carrying weapons (hunting and/or fighting) & Soaking raw materials \\
\hline Collection/transport of raw materials for tool-making & Storage of alcohol \\
\hline Concealment of dangerous objects from sight (inc. ritualized objects) & $\begin{array}{c}\text { Storage of beads } \\
\text { and body ornaments }\end{array}$ \\
\hline Cooking & Storage of colourants \\
\hline Foodstuff collection/transport (during gathering process) & Storage of drugs and medicines \\
\hline Infant cradle & Storage of equipment (various tools) \\
\hline Live animal collection/transport & Storage of foods (short and long term) \\
\hline Medicinal procedures & Storage of raw materials for tool-making \\
\hline Mixing of colourants & Storage/transport of water \\
\hline Mixing of drugs and medicines & Transport of fire \\
\hline Mixing of drinks, incl. alcohol & Traps \\
\hline Mixing of resins and glues & Treatment of the deceased \\
\hline Ritual procedures & Washing items \\
\hline This list is not exhaustive but is representative of the ethnographic literature available. \\
\hline
\end{tabular}

four questions have remained deeply influential in evolutionary reasoning (Bateson \& Laland, 2013; Nesse, 2013), especially in providing the critical distinction between ultimate (survival value, evolution) and proximate (causation, ontogeny) explanations (Scott-Phillips, Dickins \& West, 2011). Here we will address each question in turn. We find that very little is currently understood about the ontogeny of the mental capacities involved in mobile container use, and for that reason we present a pilot study that takes some initial steps towards filling out this component of Tinbergen's framework.

We consider a mobile container to be a tool used for the purpose of holding and transporting things. In its broadest sense, this definition captures diverse devices that are not prototypically 'bag-like', from simple ropes used to tie materials together to modern day containerships that can carry enormous amounts of cargo. Owing to the significant variation in tools that have carrying affordances, we focus our analysis on the shared cognitive requirements that the invention and use of these different artefacts have in common.

\section{Survival value}

The use of mobile containers has obvious functionality in that it allows humans to retain and carry materials across time and space. This ability decreases the likelihood of running out of vital resources, and so can be expected to have fitness benefits. As we will see, advantages for survival and reproduction can also flow from carrying tools that may be useful in particular future situations. Nonetheless, we do not know what pressures brought about the initial use of tools for transportation and safekeeping. Some have speculated that, following the emergence of facultative bipedal ground locomotion, the problem of transportation of infants might have led to the invention of baby slings (Falk, 2009; Taylor, 2010). Other possibilities have to do with the demands of food-gathering (Tanner and Zihlman, 1976) and food-sharing (Isaac, 1971). Although these and other accounts are plausible, there is insufficient evidence to support any one proposal at this time. What is clear, though, is that the emergence of mobile containers must have had considerable downstream effects. 
In addition to the immediate increase in carrying capacity for food, drink and sheltering materials, mobile containers created the opportunity to carry and accumulate tools. In particular, our ancestors could keep more tools available than could possibly be carried by two hands alone, which in turn makes investment in the production of additional tools increasingly beneficial. When one is able to retain tools for future use it can become profitable to spend time manufacturing more than what is immediately needed (e.g. where raw materials are available), and to carry tools that are useful only occasionally. The appearance of mobile containers thereby increased the magnitude and benefits of tool innovations and therefore probably played a critical role in driving the emergence of material culture (Langley \& Suddendorf, 2020). In a sense, mobile containers are meta-tools, that is, tools that serve as tools for other tools (Matsuzawa, 1994), and so spawned increasing reliance on toolkits rather than individual tools.

Today, mobile containers are ubiquitous and incredibly diverse. Our clothes have pockets, we have suitcases for clothes, and trolleys for suitcases. This recursive embedding creates a virtually endless variety of possible combinations. We have even invented large containers that can carry humans themselves, such as boats, cars and planes. Carrying devices are both products and facilitators of our extraordinary cumulative culture, typically filled with artefacts that themselves reflect this material culture. Mobile containers have allowed humans to maintain a local artificial habitat that contains critical resources and the means to fulfil needs, from a knife, to a fire-making kit, to sewing needles. In an important sense, the use of mobile containers has its roots in our capacity to think ahead and to ready ourselves for challenges before they are upon us (Suddendorf, 2006). Indeed, carrying devices enable us to be prepared for all manner of specific future eventualities. This basic capacity for foresight is also probably the key underpinning mechanism, discussed further below, that enabled us to devise these tools in the first place.

\section{Evolution}

Some animals have evolved natural carrying compartments, such as marsupials with pouches to carry offspring and pelicans with throat sacks to carry food. Although it has been argued that non-human primates have only limited use of containers (McGrew, 1992), some animals have on occasion been observed using external containers (see Table 2). However, they do not show much behavioural flexibility or foresight (Suddendorf \& Corballis, 1997; Suddendorf, 2013). While many species use tools and some even make them, there is little to suggest any other animals recognize the future utility of carrying devices. As we will see in the Causation section, humans can reflect on their own limits and devise ways to physically offload tasks, and then refine them further for more effective long-term use. If these behaviours are uniquely human traits, they are likely to have evolved in hominins over the 6 million years after the split from the line leading to modern chimpanzees.

The role of containers in human history has become the topic of considerable interest and debate (e.g. Shryock \& Smail, 2018). Containers in the form of pottery and baskets have been documented extensively from the late Neolithic (e.g. Nieuwenhuyse, 2019), but their roots are much more ancient. As already noted, there has been speculation that the earliest hominin mobile containers were baby slings (e.g. Bolen, 1992; Ehrenberg, 1989; Falk, 2009; Fisher, 1979), and that containers for gathering would have been useful to Australopithecines over 3 million years ago (Tanner \& Zihlman, 1976). However, just because something would have been useful does not mean that it was used. We do not currently know what the original adaptive function was and when it first emerged. Evidence for the transport of raw materials over long distances points back to the Oldowan and Acheulean, but this behaviour only appears to become a regular feature by the second half of the Middle Stone Age (Ambrose, 2012; McBrearty \& Brooks, 2000). Even then, it remains possible that transportation could have been achieved without mobile containers. Similarly, because open water appears to have served as a barrier to pre-sapiens populations, evidence for the colonization of islands has been seen to reflect modern cognitive abilities - in particular, that the construction and provisioning of a watercraft (as a mobile container to carry goods and people) required levels of foresight unavailable 
Table 2. Some examples of animal container use

\begin{tabular}{|c|c|c|}
\hline Animal & Container use observed & Reference \\
\hline $\begin{array}{l}\text { African Grey Parrots, } \\
\text { Cockatoos }\end{array}$ & Using nutshells, moss, and a variety of human-made containers, to drink water & $\begin{array}{l}\text { Boswall (1983); Pepperberg and Shive (2001); Shumaker } \\
\text { et al. (2011) }\end{array}$ \\
\hline Ants (some species) & $\begin{array}{l}\text { Use pieces of leaf, wood or grass to transport viscous liquids such as honey, fruit } \\
\text { pulp or body fluids of prey back to the colony }\end{array}$ & Banschbach et al. (2006) \\
\hline Bonobo (in captivity) & $\begin{array}{l}\text { Placed a large amount of food on wood-wool, which she then dragged in her } \\
\text { enclosure }\end{array}$ & Walraven et al. (1993) \\
\hline $\begin{array}{l}\text { Capuchin Monkeys, } \\
\text { Orangutans, Chimpanzees }\end{array}$ & $\begin{array}{l}\text { Use leaves to scoop up water (chimpanzees in Bossou even fold leaves at about } \\
3 \mathrm{~cm} \text { intervals between pleats and so they better retain liquid) }\end{array}$ & $\begin{array}{l}\text { Knott (1999); Phillips (1998); Tonooka (2001); van } \\
\text { Lawick-Goodall (1968) }\end{array}$ \\
\hline \multicolumn{3}{|c|}{ leaf litter and then move the } \\
\hline Chimpanzees (at Gombe) & $\begin{array}{l}\text { Sometimes defecate onto leaves while holding them, to then forage for } \\
\text { undigested meat amongst the faeces }\end{array}$ & Goodall (1986) \\
\hline Chimpanzees (in captivity) & Use coconut shells to collect water & McGrew (1992) \\
\hline Crow & Transported food with a cup and a Frisbee & Shumaker et al. (2011) \\
\hline Gorilla (in captivity) & Used a box as a tray, carrying his food around bipedally & Vancatova (2008) \\
\hline Marsh tit (in captivity) & $\begin{array}{l}\text { Detached a paper sticker from its feeder and used the sticky side to pick up } \\
\text { powdered food from its bowl and transport it to its perch }\end{array}$ & Clayton and Jolliffe (1996) \\
\hline $\begin{array}{l}\text { New world Monkeys, } \\
\text { Old world monkeys, } \\
\text { Great apes }\end{array}$ & $\begin{array}{l}\text { Use of human-made containers (cups, etc.) for drinking water. Some transfer of } \\
\text { water over a few metres }\end{array}$ & $\begin{array}{l}\text { Jordan (1982); Parks and Novak (1993); Russon, et al. } \\
\text { (2010); Westergaard and Fragaszy (1985) }\end{array}$ \\
\hline Orangutan (in captivity) & Filled a tub with straw and transported it outside to make a nest & Shumaker et al. (2011) \\
\hline Sea otter & $\begin{array}{l}\text { Immobilize crabs by wrapping them in kelp and then carry the crabs on their } \\
\text { belly while consuming other foods }\end{array}$ & Riedman and Estes (1990) \\
\hline
\end{tabular}


to archaic hominins (Carter et al., 2019; Ingicco et al., 2018; Leppard, 2015). However, some archaeological discoveries have suggested that such technologies were not necessary to reach islands, and that other processes that did not require advanced planning may have been at work (Brumm et al., 2010; see Leppard 2015 for discussion). The oldest hard evidence for a boat is the Mesolithic 'Pesse canoe', found in Assen, Netherlands and dated to about 10,000 years old (Wierenga, 2001).

A recent review of the archeological evidence for mobile containers in the deep past highlights the difficulty of pinpointing the origins and development of these tools. Langley and Suddendorf (2020) found the oldest signs in the archeological record to only date back to about 100,000 years BP. At Blombos (South Africa) and at Qafzeh (Israel) Homo sapiens and Neanderthals, respectively, seem to have stored ochre in natural shell containers. If one conceives of necklaces as containers, given that they can contain and transport shells, beads and other objects, then the date can be pushed back further to $130,000 \mathrm{BP}$, as indicated by white-tailed eagle talons showing cut marks and wear patterns, suggesting that they had been worn by Neanderthals as personal adornment (Radovčić et al., 2015). However, shells or talons appear to be part of the adornment, rather than material to be transported (just as a stone tip can be part of a spear without the stick being considered a mobile container for the stone). The earliest signs of manufactured containers made from stalagmite and wood appear from about 50,000 BP (Carbonell et al., 1996; Cârciumaru et al., 2002, 2015). Evidence for baskets, nets, and pots appears later still, around 30,000 BP, although Hardy et al. (2020) recently reported a small piece of three-ply cord made from inner bark fibres found at a Neanderthal site dated to between 41,000 and 52,000 years BP, which may imply that perishable containers were also present at this antiquity.

The absence of evidence for containers earlier in the archeological record does not necessarily entail evidence for absence (Gamble, 2007). The relatively recent appearance probably reflects the highly perishable nature of the raw materials, and we will need to consider indirect evidence for container construction, for instance, that the 75,000-year-old engraved ochre nodules at Blombos represent instructions for weaving techniques (Anderson, 2020). Langley and Suddendorf (2020) caution that the relatively recent appearance of evidence for mobile containers may also reflect a certain lack of attention to these devices in studies on human evolution. Their association with gathering and 'women's work' may have elicited less interest than evidence for hunting (Ehrenberg, 1989; Gero, 1991), and more traces of container technology may be described once this bias is redressed.

\section{Causation}

Given that modern mobile containers range from wallets to backpacks, and from shopping trolleys to cargo containers, the cognitive mechanisms involved in their construction will be diverse. Fundamentally, however, the key first step is the recognition that an object can have a holding and a transporting affordance. For instance, a hollow object such as a gourd or an ostrich egg, or a concave object such as a shell or a tortoise carapace, can be filled and carried. Rather than carrying resources directly in our hands, these objects allow us to 'offload' the work of retention to a separate structure often better suited to containing the resource. For the price of having to carry the additional weight of the container, we can be finished with the task of containing - leaving us to only transport the filled container. This trade-off can enable us to carry more material, and often frees our hands for other tasks as well.

We can do much more when we not only recognize immediate utility, but also anticipate the future utility of an object. By thinking ahead and considering forthcoming challenges, we can realize what we may need to do now to help us in the future. Recognizing the future utility of solutions is the aspect of foresight that drives us to retain objects that will be useful again, even if they offer nothing in the present moment. It also motivates us to enhance tools, to refine them further so that they become more effective, efficient and reliable. It has been argued that recognition of future utility is essentially what turns a problem solution into an innovation (Suddendorf et al., 2018; von Hippel \& Suddendorf, 2018). Without it, the best solutions to problems would be tossed aside once the task was done. 
However, with recognition of future utility, we are compelled to retain the object, to protect it, to refine it and possibly to share it with others.

Foresight allows us to anticipate problems, including issues caused by the limits of our physical and mental capacities (Bulley, Redshaw \& Suddendorf, 2020). Once we can reflect on the fact that there are limits to our capacities, we can devise ways of compensating for them. Mobile containers enable us to carry great numbers of items more comfortably, after anticipating both (a) the need for objects in the future and (b) one's own inability to carry those objects without an external aid. This physical offloading has a parallel to what has come to be known as cognitive offloading (Risko \& Gilbert, 2016). For instance, because we understand that our memory may let us down in the future, we use external reminders - from knots in handkerchiefs to digital alarms - to ensure that we will remember (Gilbert, 2015; Redshaw et al., 2018b). In this way, humans routinely make thinking easier: taking notes, using calculators and relying on satellite navigation systems. Cognitive offloading enables us to 'extend' our mental capacities well beyond their natural limits (Clark \& Chalmers, 1998), and is central to modern notions of intelligence (Bocanegra et al., 2019). However, physical offloading is probably similarly important for understanding how humans have been able to transform the planet. Tools that extend our physical capacities, from bags to bulldozers, have allowed us to dramatically change our habitats and construct new niches like no other creature could, creating artificial worlds that suit our anticipated needs.

Risko and Gilbert's (2016) influential account of cognitive offloading distinguishes between actions that offload mental processes onto the body (e.g. using finger counting) and actions that offload mental processes into the world (e.g. using an abacus). A related distinction can be made in the use of mobile carrying devices to transport items, in that a choice is made to offload physical labour onto an external artefact rather than to solely depend on the body. Often, this choice arises from understanding the limits of one's natural carrying capacity, and seeking to expand this limit through artificial means.

\section{Ontogeny}

The development of foresight has become a hot topic in child psychology. Various lines of evidence suggest that children gradually acquire basic capacities over the preschool years (Atance, 2015; Suddendorf, 2017), but that developments continue into late childhood and beyond (Ghetti \& Coughlin, 2018; Suddendorf \& Redshaw, 2013). Recent studies also suggest that even preschool-aged children can recognize their cognitive limits and compensate for them with into-the-world cognitive offloading (Armitage et al., 2020; Bulley et al., 2020). Nonetheless, we are not aware of any studies directly examining children's appreciation of the utility of mobile containers as physical offloading devices, although even young infants may have some understanding of the general concept of containment (Hespos \& Baillargeon, 2001), and four-year-olds can secure a tool in a provided container for a return to a problem they had encountered earlier (Redshaw \& Suddendorf, 2013). Studying the use of mobile containers offers a new testbed for tracking the early emergence of the capacities involved in anticipating one's own limits and compensating for them. To examine at what point children can reflect on their own physical limits sufficiently to initiate compensatory strategies, we designed the following pilot study of children's understanding and use of mobile containers.

\section{Methods}

\section{Participants}

Participants were recruited from a database of parents who expressed interest in their child participating in research at the Early Cognitive Development Centre of University of Queensland, Australia. The final sample included 106 children between the ages of 3 and 7, who were subdivided into five age categories: 3-year-olds $\left(n=21, M_{\text {age }}=40.52\right.$ months, $\mathrm{SD}_{\text {age }}=1.52$ months, 10 female $), 4$-year-olds $\left(n=24, M_{\text {age }}=53.65\right.$ months, $\mathrm{SD}_{\text {age }}=2.39$ months, 12 female $)$, 5-year-olds $\left(n=22, M_{\text {age }}=67.59\right.$ months, $\mathrm{SD}_{\text {age }}=3.46$ months, 14 female), 6-year-olds $\left(n=20, M_{\text {age }}=76.65\right.$ months, $\mathrm{SD}_{\text {age }}=4.03$ 


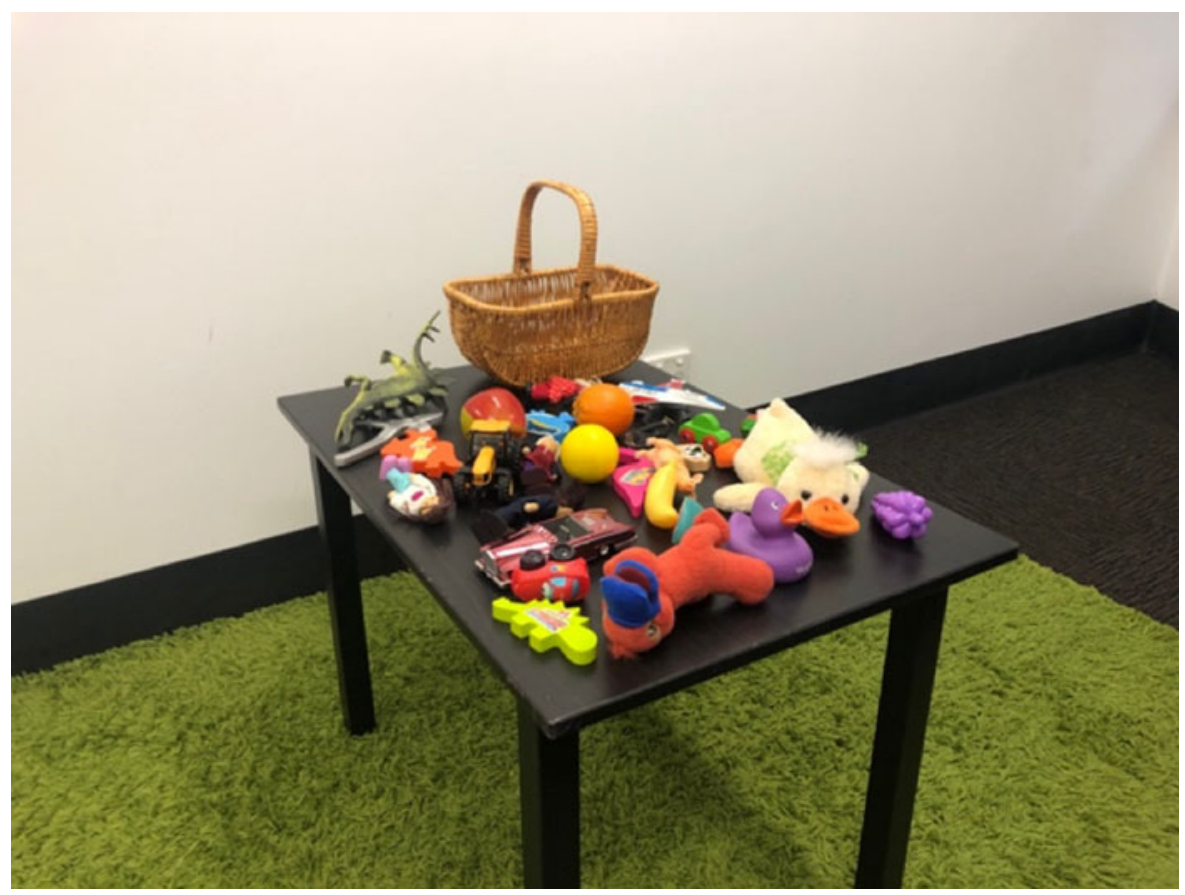

Figure 1. Image of the second experimental room.

months, 8 female) and 7-year-olds $\left(n=19, M_{\text {age }}=92.68\right.$ months, $\mathrm{SD}_{\text {age }}=3.79$ months, 11 female $)$ A post-hoc power analysis indicated that this sample provided an $88.4 \%$ chance of detecting a medium linear effect of age $(r=0.30)$, and a $>99.9 \%$ chance of detecting a large effect $(r=0.50)$. Age effects of such sizes have been previously observed in studies of children's abilities to consider their future (cognitive) limitations (e.g. Redshaw \& Suddendorf, 2016; Redshaw et al., 2018a). Ethical approval was granted by the UQ Human Research Ethics Committee (2018000401).

\section{Materials}

The first experimental room contained a stuffed toy tiger named 'Tigger'. Additionally, this room contained a sheet of stickers that children would later receive as a reward. The second experimental room was located approximately 5 metres' walk from the first room and contained a stuffed 'Mickey Mouse' toy sitting on a chair. This second room also contained a small table with 30 items spread on its surface. Of the items, 29 were various sized toys and one item was a stereotypical Western woven basket (see Figure 1).

\section{Procedure and measures}

The experimenter led children into the first room and pointed out Tigger, before providing the following instructions:

This is Tigger's Room, and he wants to play some games here. But there are no toys here for him to play with. The room next door is Mickey Mouse's room and Mickey has lots of toys. You're going to try bring back as many toys as you can for Tigger. The more toys you bring back, the more stickers you will get from Tigger. 
The experimenter then asked children to walk to the second room and pointed out Mickey Mouse, saying: 'This is Mickey Mouse's room and these are his toys. He wants you to give some of these toys to Tigger'. The experimenter then pointed out five items, with the third item always being the basket (i.e. 'We have a [toy name], a [toy name], a basket, a [toy name] and a [toy name]'). This was to ensure children were aware the basket was one of the items they could take without prompting them to use it. The experimenter then stated:

We don't have much time before we go back to Tigger's Room. Please take as many toys as you can in one go back to Tigger. Remember, the more toys you take, the more stickers Tigger will give you.

The number of items was large enough to ensure that the children could not carry all of the toys without a carrying device. If the children asked for help, they were told 'Just take as much as you can in one go'. Additionally, if children asked permission to use the basket, they were told 'You can do whatever you want to'. The number of items children took (i.e. 0-30) and whether children used the basket (i.e. yes/no) were recorded. Children collected the items and the experimenter showed them back to the first room. The items were given to Tigger and the children were rewarded with stickers.

The children were then asked a series of questions. If they had not used the basket, they were asked, 'Could you have carried any more toys somehow?' This measure was coded as (1) yes or (2) no. If children elaborated on how they could have carried toys, their response was coded as (1) using a part of their body, (2) use a mobile-carrying device, or (3) other. Further, children who had not used the basket were asked, 'Did you see the basket in Mickey's room?', and the response was coded as (1) yes or (2) no. Regardless of whether children had used the container or not, they were then asked, 'What do adults do when they have to carry more than they can hold in their hands?' This variable was coded as (1) use a mobile-carrying device, (2) use the body, (3) social help and (4) no solution.

\section{Results and discussion}

First, we assessed whether older children used the basket more than younger children. A binomial logistic regression examining the effect of age in months on basket usage was statistically significant, $\chi^{2}(1)=9.81, p=0.002$, with increases in age associated with a higher likelihood of children using the basket, $b=0.04, \mathrm{SE}=0.01, p=0.003$. The model explained $11.8 \%$ (Nagelkerke $R^{2}$ ) of the variance in basket usage and correctly classified $61.3 \%$ of cases. As shown in Figure 2, the proportion of children using the basket increased roughly linearly with age, from $23.8 \%$ of 3 -year-olds to $79.0 \%$ of 7-year-olds.

Next, we assessed whether older children and those who used the basket carried more items. A multiple linear regression examining the effects of age in months and basket usage on number of items carried was statistically significant $(F[2,103]=96.85, p<0.001)$, with an $R^{2}$ of 0.653 . The number of items carried significantly increased with age, $b=0.16, \mathrm{SE}=0.03, p<0.001$, and when children used the basket, $b=12.56, \mathrm{SE}=1.15, p<0.001$.

Descriptive statistics are provided for children's responses to the qualitative questions. Of the 48 children who did not use the basket, 37 (77.1\%) claimed that they could have carried more items, with 18 elaborating on how they could do so (nine stated that they could use some part of their body, seven mentioned mobile containers and two provided other responses). Seven (14.6\%) of these 48 children claimed that they did not see the basket in Mickey's room despite it being pointed out.

All children $(N=106)$ were asked their perceptions of what adults do when they have too many items: $42.5 \%$ of children mentioned a mobile container, $41.5 \%$ provided no solution, $11.3 \%$ stated adults could get social help and $4.7 \%$ said they could use some part of their body. A binomial logistic 
A. Percentage of children using bag by age

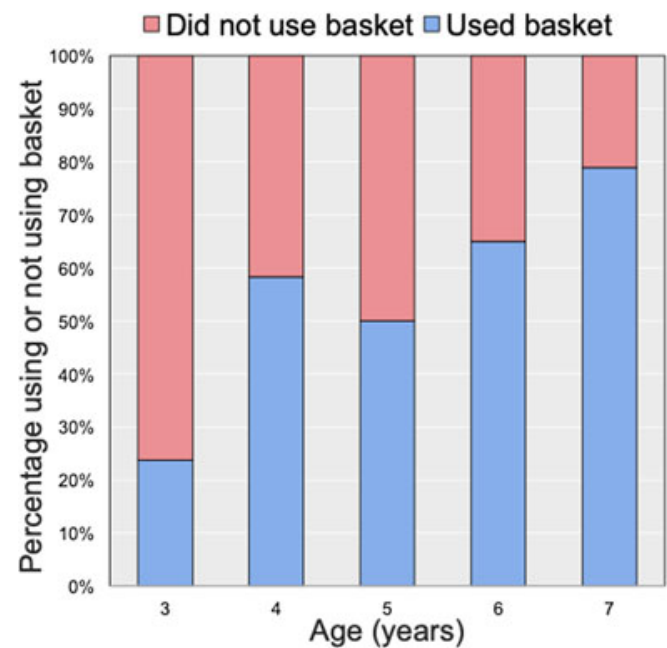

\section{B. Items carried and use of bag by age}

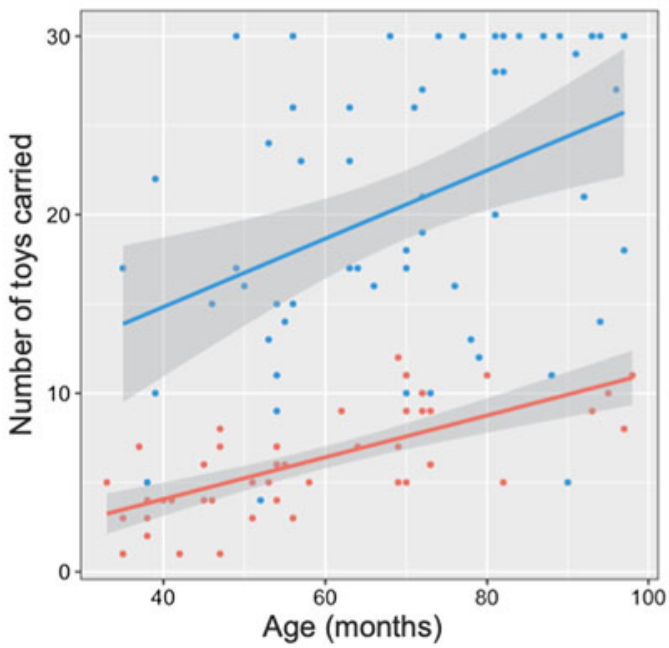

Figure 2. Percentage of children using the bag across age in years (A). There was a linear increase in the use of the bag with age. Number of items carried depending on whether children carried the bag or not across age in months (B). Children carried more items when they used the bag, and performance improved with age.

regression examined the effect of age (in months) on answering this question with some form of a mobile container. The logistic regression model was statistically significant, $\chi^{2}(1)=7.30, p=0.007$, with increases in age associated with a higher likelihood of children mentioning a mobile container, $b=0.03, S E=0.01, p=0.009$. The model explained $8.9 \%$ (Nagelkerke $R^{2}$ ) of the variance in mentioning mobile containers and correctly classified $59.4 \%$ of cases.

The results of this first study on children's understanding and use of mobile containers suggests that there is considerable early competence. In line with informal observations, young children can use containers to retain and transport materials. Many realize that they can enhance their carrying capacity by using such tools. Yet spontaneous use of a basket to increase their own carrying capacity was only observed in less than a quarter of 3-year-olds. Future research is imperative to examine other facets of early container use and understanding, and its relation to other aspects of cognitive development (Dunbar, 2003; Suddendorf \& Redshaw 2013; Stade, 2020). Of particular interest will be examination of how children recognize the future utility of these tools - not just of present utility as examined in this study. It will also be critical to our understanding of the underlying mechanisms to assess the relationship of container use to other measures of foresight.

Controlled experiments will probably play a large role in building our understanding of this development, as ethnographic data pertaining to children's use of containers is limited. Early ethnographers were largely uninterested in children, and thus, we have only slim insights into their daily activities (Langley \& Litster, 2018). There are, however, frequent mentions of children enjoying mimicking the behaviours of their parents (and other adults in their community), which includes making woven baskets (Figure 3; Gosso \& Otta 2003) and clay pots (e.g. Crown 2001), among other container types.

\section{Conclusion}

Although non-human animals sometimes use containers, current evidence suggests that only humans recognize the future utility of such devices. Today, mobile containers are all around us. They are so ubiquitous that it is easy to overlook the fundamental importance of this humble innovation. Indicators of manufactured mobile containers in the archeological record appear from around 50,000 years ago, comprising a cord fragment and a couple of wooden and stalagmite containers. 


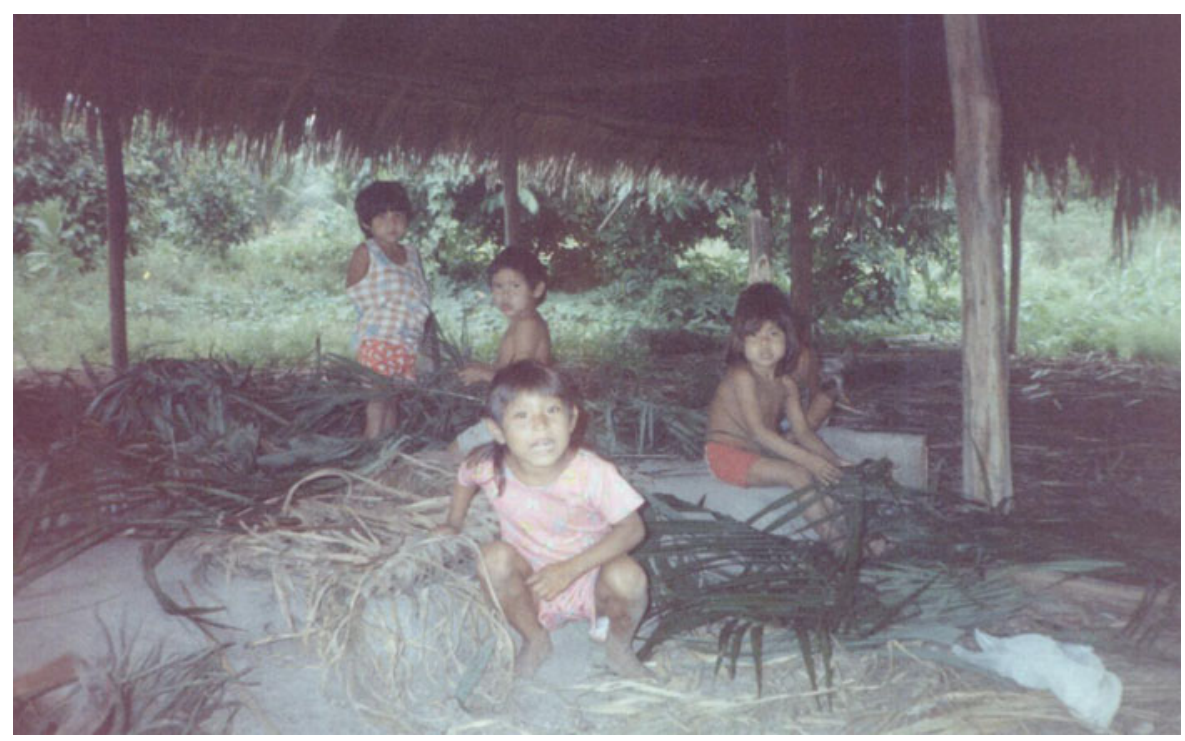

Figure 3. Parakanã children playing at weaving baskets in Brazil (photograph courtesy of Y. Gosso).

Natural containers for ochre processing, such as shells and eggshells, are evident from 100,000 years ago, but this need not entail recognition of future utility or even actual transportation. Yet, we suspect that hominins started relying on mobile containers considerably earlier than either of these dates, perhaps around the time when more tools and especially smaller tools become common in the archeological record.

The emergence of mobile containers in hominin evolution probably drove the innovation of further tools and the ratcheting of ever more sophisticated material culture. With carrying devices our ancestors could obtain a selective advantage by making diverse tools in advance wherever the best resources were. We argue that the appearance of such devices reflects an important milestone in cognitive evolution and development: the capacity to think about one's own limits and compensate for them. This was a game changer. Mobile containers allowed our ancient forebears to maintain a local habitat - to have tools and resources at the ready wherever they went.

In the pilot study, we here demonstrated that even 3-year-old children show some aptitude to use mobile containers to increase carrying capacity and secure immediate benefits. Further studies may examine how children across cultures first begin to recognize the future utility of containers and the items they carry, as well as the role of social learning in this development.

Acknowledgements. We would like to thank the participating children and their parents, as well as Sally Clark at the UQ Early Cognitive Development Centre.

Author contributions. TS wrote the first draft of the article. ML and TS reviewed the comparative and archaeological evidence. TS, JR, $\mathrm{AB}$ and $\mathrm{KK}$ designed the developmental study, and KK collected the developmental data. TS, JR, AB, KK and MCL edited the article manuscript.

Financial support. Aspects of this research was funded by an Australian Research Council DECRA (DE170101076) to MCL. AB is supported by an Australian National Health and Medical Research Council CJ Martin Biomedical Fellowship APP1162811.

Conflict of interest declarations. The authors report no conflict of interest.

Research transparency and reproducibility. The data sheets are available at https://osf.io/zadqy/?view_only= 3c86f0585ebd44538e794d6c3aeec189 


\section{References}

Ambrose, S. H. (2012). Obsidian dating and source exploitation in Africa. Implications for the evolution of Human behavior. In I. Liritzis \& C. M. Stevenson (Eds.), Obsidian and ancient manufactured glasses (pp. 46-62). University of New Mexico Press.

Anderson, H. (2020). Impressions and expressions: Searching for the origins of basketry. In Basketry and beyond: Constructing culture. Brill.

Armitage, K. L., Bulley, A., \& Redshaw, J. (2020). Developmental origins of cognitive offloading. Proceedings of the Royal Society B, 287, 20192927.

Atance, C. M. (2015). Young children's thinking about the future. Child Development Perspectives, 9, $178-182$.

Banschbach, V. S., Brunelle, A., Bartlett, K. M., Grivetti, J. Y., \& Yeamans, R. L. (2006). Tool use by the forest ant Aphaenogaster rudis: Ecology and task allocation. Insectes Sociaux 53, 463-471.

Bateson, P., \& Laland, K. N. (2013). Tinbergen's four questions: an appreciation and an update. Trends in Ecology and Evolution, 28, 712-718.

Bocanegra, B. R., Poletiek, F. H., Ftitache, B., \& Clark, A. (2019). Intelligent problem-solvers externalize cognitive operations. Nature Human Behavior, 3, 136-142.

Bolen, K. M. (1992). Prehistoric construction of mothering. In C. Classen (Ed.) Exploring gender through archaeology (pp. 49-62). Prehistory Press.

Boswall, J. (1983). Tool-using and related behaviour in birds: More notes. Avicultural Magazine, 89, 94-108.

Brumm, A., Jensen, G. M., van den Bergh, G. D., Morwood, M. J., Kurniawan, I., Aziz, F., \& Storey, M., (2010). Hominins on Flores, Indonesia, by one million years ago. Nature, 464, 748-752.

Bulley, A., McCarthy, T., Gilbert, S. J., Suddendorf, T., \& Redshaw, J (2020). Children devise and selectively use tools to offload cognition. Current Biology, 30, 1-8.

Bulley, A., Redshaw, J., \& Suddendorf T. (2020). The future-directed functions of the imagination: From prediction to metaforesight. In A. Abraham (Ed.), The Cambridge handbook of the imagination. Cambridge University Press.

Carbonell, E., Cebrià, A., Allué, E., Cáceres, I., Castro, Z., Díaz, R., Esteban, M., Ollé, A., Pastó, I., Rodriguez, X. P., Rosell, J., Sala, R., Vallverdú, J., Vaquero, M., and Vergés, J. M. (1996). Behavioural and organizational complexity in the Middle Palaeolithic from the Abric Romani. In E. Carbonell (Ed.), The last Neanderthals, the first anatomically modern humans (pp. 385-434). Universitat Rovira i Virgili.

Cârciumaru, M., Moncel, M.-H., Anghelinu, M., \& Cârciumaru, R. (2002). The Cioarei-Borosteni Cave (Carpathian Mountains, Romania): Middle Palaeolithic finds and technological analysis of the lithic assemblages. Antiq, 76, 681-690.

Cârciumaru, M., Nițu, E.-C., \& Cîrstina, O. (2015). A geode painted with ochre by the Neanderthal man. Comptes Rendus Palevol, 14, 31-41.

Carter, T., Contreras, D. A., Holcomb, J., Mihailović, D. D., Karkanas, P., Guérin, G., Taffin, N., Athanasoulis, D., \& Lahaye, C. (2019). Earliest occupation of the Central Aegean (Naxos), Greece: Implications for hominin and Homo sapiens' behavior and dispersals. Science Advances, 5, eaax0997.

Clark, A., \& Chalmers, D. J. (1998) The extended mind. Analysis, 58, 7-19.

Clayton, N. S., \& Jolliffe, A. (1996). Marsh tits Parus palustris use tools to store food. IBIS, 138, 554.

Crown, P. L. (2001). Learning to make pottery in the prehispanic American southwest. Journal of Anthropological Research, 57, 451-469.

Dunbar, R. I. M. (2003). The social brain: Mind, language, and society in evolutionary perspective. Annual Review of Anthropology, 32, 163-181.

Ehrenberg, M. (1989). Women in Prehistory. British Museum Publications.

Falk, D. (2009). Finding our tongues: Mothers, infants and the origins of language. Basic Books.

Fisher, E. (1979). Woman's creation: Sexual evolution and the shaping of society. Anchor Press.

Gamble, C. S. (2007). Origins and revolutions: Human identity in earliest prehistory. Cambridge University Press.

Gero J. (1991). Genderlithics: Women's roles in stone tool production. In J. M. Gero \& J. M. Conkey (Eds.), Engendering archaeology: Women and prehistory (pp. 163-193). Blackwell Publishing.

Ghetti, S., \& Coughlin, C. (2018). Stuck in the present? Trends in Cognitive Science, 22, 846-850.

Gilbert, S. J. (2015). Strategic use of reminders: Influence of both domain-general and task-specific metacognitive confidence, independent of objective memory ability. Consciousness \& Cognition, 33, 245-260.

Goodall, J. (1986). The chimpanzees of Gombe: Patterns of behaviour. Harvard University Press.

Gosso, Y., \& Otta. E. (2003). Em uma aldeia Parakanã. In A. M. A. Carvalho, C. M. C. Magalhães, F. A. R. Pontes, \& I. D. Bichara, (Eds.) Brincadeira é cultura: viajando pelo Brasil que brinca (pp. 33-76). São Paulo: Casa do Psicólogo.

Hardy, B. L., Moncel, M. H., Kerfant, C., Lebon, M., Bellot-Gurlet, L., \& Mélard, N. (2020). Direct evidence of Neanderthal fibre technology and its cognitive and behavioral implications. Scientific Reports 10, 4889.

Hespos, S. J., \& Baillargeon, R. (2001). Infants' knowledge about occlusion and containment events. Psychological Science, $12,141-147$.

Ingicco, T., van den Bergh, G. D., Jago-on, C. Bahain, J. J., Chacón, M. G., Amano, N., Forestier, H., King, C., Manalo, K., Nomade, S., Pereira, A., Reyes, M. C., Sémah, A. M., Shao, Q., Voinchet, P., Falguères, C., Albers, P. C. H., Lising, M., 
Lyras, G., Yurnaldi, D., Rochette, P., Bautista, A., \& de Vos, J. (2018). Earliest known hominin activity in the Philippines by 709 thousand years ago. Nature, 557, 233-237.

Isaac, G. (1971). The diet of early man: Aspects of archaeological evidence from Lower and Middle Pleistocene sites in Africa. World Archaeology, 2, 278-299.

Jordan, C. (1982). Object manipulation and tool-use in captive pygmy chimpanzees (Pan paniscus). Journal of Human Evolution, 11, 35-39.

Keenleyside, M. H. A., \& Prince C. E. (1976). Spawning-site selection in relation to parental care of eggs in Aequidens paraguayensis (Pisces: Cichlidae). Canadian Journal of Zoology, 54, 2135-2139.

Knott, C. (1999). Orangutan behavior and ecology. In P. Dolhinow \& D. Fuentes (Eds). The nonhuman primates (pp. 50-57). Mayfield.

Langley, M. C., \& Litster, M. (2018). Is it ritual? Or is it children?: Distinguishing consequences of play from ritual actions in the prehistoric archaeological record. Current Anthropology, 59, 616-643.

Langley, M. C., \& Suddendorf, T. (2020). Mobile containers in human cognitive evolution studies: Understudied and underrepresented. Evolutionary Anthropology. doi: 10.1002/evan.21857

Leppard, T. P. (2015) Passive dispersal versus strategic dispersal in island colonization by hominins. Current Anthropology, $56,590-595$.

Matsuzawa, T. (1994). Field experiments on use of stone tools by chimpanzees in the wild. In R. W. Wrangham, W. C. McGrew, F. B. M. de Waal, \& P. G. Heltne (Eds.), Chimpanzee cultures (pp. 351-370). Harvard University Press.

McBrearty, S., \& Brooks, A. S. (2000). The revolution that wasn't: A new interpretation of the origin of modern human behavior. Journal of Human Evolution, 39, 453-463.

McGrew, W. C. (1992). Chimpanzee material culture: implications for human evolution, Cambridge University Press.

Nesse, R. M. (2013) Tinbergen's four questions, organized: A response to Bateson and Laland. Trends in Ecology and Evolution, 28, 681-682.

Nieuwenhuyse, O. (2019). Containers and creativity in Late Neolithic Upper Mesopotamia. In I. Hodder (Ed.), Consciousness and creativity at the dawn of settled life. Cambridge University Press.

Parks, K., \& Novak, M. (1993). Observations of increased activity and tool use in captive rhesus monkeys exposed to troughs of water. American Journal of Primatology, 29, 13-25.

Pepperberg, I. M. \& Shive, H. R. (2001). Simultaneous development of vocal and physical object combinations by a grey parrot (Psittaus erithacus): Bottle caps, lids, and labels. Journal of Comparative Psychology, 115, 376-384.

Phillips, K. A. (1998). Tool use in wild capuchin monkeys (Cebus albifrons trinitatis). American Journal of Primatology, 46, 259-261.

Radovčić, D., Sršen, A. O., Radovčić, J., \& Frayer, D. W. (2015). Evidence for neandertal jewelry: Modified white-tailed eagle claws at Krapina. PLoS ONE, 10, e0119802. https://doi.org/10.1371/journal.pone.0119802.

Redshaw, J., Leamy, T., Pincus, P., \& Suddendorf, T. (2018a). Young children's capacity to imagine and prepare for certain and uncertain future outcomes. PloSONE. https://doi.org/10.1371/journal.pone.0202606.

Redshaw, J., \& Suddendorf, T. (2013). Foresight beyond the very next event: Four-year-olds can link past and deferred future episodes. Frontiers of Psychology 4, 404. doi: 10.3389/fpsyg.2013.00404.

Redshaw, J., \& Suddendorf, T. (2016). Children's and apes' preparatory responses to two mutually exclusive possibilities. Current Biology, 26, 1758-1762.

Redshaw, J., Vandersee, J., Bulley, A., \& Gilbert, S. J. (2018b). Development of children's use of external reminders for hard-to-remember intentions. Child Development, 89, 2099-2108.

Riedman, M. L., \& Estes, J. A. (1990). The sea otter (Enhydra lutris): Behavior, ecology, and natural history. U.S. Fish and Wildlife Service Biological Reports, 90, 126.

Risko, E. F., \& Gilbert, S. J. (2016). Cognitive offloading. Trends in Cognitive Sciences, 20, 676-688.

Russon, A. E., Kuncoro, P., Ferisa, A., \& Handayani, D. P. (2010). How orangutans (Pongo pygmaeus) innovate for water. Journal of Comparative Psychology, 124, 14-28.

Scott-Phillips, T. C., Dickins, T. E., \& West, S. A. (2011). Evolutionary theory and the ulitmate-proximate distinction in the human behavioral sciences. Perspectives in Psychological Science, 6, 38-47.

Shryock, A., \& Smail, D. L. (2018). On containers: A forum. Introduction. History and Anthropology, 29, 1-6.

Shumaker, R. W., Walkup, K. R., \& Beck, B. B. (2011). Animal tool behavior. Johns Hopkins University Press.

Stade, C. (2020). Theory of mind as a proxy for Palaeolithic language ability. Language Dynamics and Change, 1, 1-27.

Suddendorf, T. (2006). Foresight and the evolution of the human mind. Science, 312, 1006-1007.

Suddendorf, T. (2013). The gap: The science of what separates us from other animals. Basic Books.

Suddendorf, T. (2017). The development of episodic foresight and its consequences. Child Development Perspectives, 11, 192-195.

Suddendorf, T., Bulley, A. \& Miloyan, B. (2018). Prospection and natural selection. Current Opion in Behavioral Sciences, $24,26-31$.

Suddendorf, T., \& Corballis, M. C. (1997). Mental time travel and the evolution of the human mind. Genetic, Social and General Psychology Monographs, 123, 133-167. 
Suddendorf, T., \& Redshaw, J. (2013). The development of mental scenario building and episodic foresight. The Year in Cognitive Neuroscience 2013: Annals of the New York Academy of Science, 1296, 135-153.

Tanner, N., \& Zihlman, A. (1976). Women in evolution. Part I: Innovation and selection in human origins. Signs: Journal of Women in Culture and Society, 1, 585-608.

Taylor, T. (2010). The artificial ape. How technology changed the course of human evolution. Palgrave MacMillan.

Tinbergen, N. (1963). On aims and methods of ethology. Zeitschrift fuer Tierpsychologie, 20, 410-433.

Tonooka, R. (2001). Leaf-folding behavior for drinking water by wild chimpanzees (Pan trologytes verus) in Bossou, Guinea. Animal Cognition, 4, 325-334.

Vancatova, M. A. (2008). Tool use behaviour of western lowland gorillas (Gorilla gorilla gorilla) in captivity. Folia Primatologica, 79, 395.

van Lawick-Goodall, J. (1968). The behaviour of free-living chimpanzees in the Gombe Stream Reserve. Animal Behaviour Monographs. Baillière, Tindall, \& Cassel.

von Hippel, W., \& Suddendorf, T. (2018). Did humans evolve to innovate with a social rather than technical orientation? New Ideas in Psychology, 51, 34-39.

Walraven, V., van Elsacker, L., \& Verheyen, R. (1993). Spontaneous object manipulation in captive bonobos (Pan paniscus). Bonobo Tidings, 25-34.

Westergaard, G. C., \& Fragaszy, D. M. (1985). Effects of manipulatable objects on the activity of captive capuchin monkeys (Cebus apella). Zoobiology, 4, 317-327.

Wierenga, J. (2001). Kano Van Pesse Kon Echt Varen. Nieuwsblad van het Noorden, 12 April.

Cite this article: Suddendorf T, Kirkland K, Bulley A, Redshaw J, Langley MC (2020). It's in the bag: mobile containers in human evolution and child development. Evolutionary Human Sciences 2, e48, 1-13. https://doi.org/10.1017/ehs.2020.47 